\title{
CULTURAS POPULARES E POLÍTICAS CULTURAIS NO BRASIL: A NAÇÃO E SUAS MARGENS
}

\author{
POPULAR CULTURES AND CULTURAL POLICIES IN BRAZIL: \\ NATION AND ITS MARGINS
}

\author{
Caio Csermak ${ }^{1}$
}

Recebido em: 31/07/2012

Aprovado em: 18/11/2013

\begin{abstract}
RESUMO
O presente artigo aborda as políticas públicas do Ministério da Cultura (MinC) com foco nas culturas populares durante o período 2003-2010 (gestões Gilberto Gil e Juca Ferreira). Para isso, discorro sobre a relação entre Estado, academia e culturas populares no Brasil, buscando compreender o processo de apropriação seletiva destas por um Estado homogeneizante e uma produção acadêmica reificadora. Tal processo não ocorreu sem um movimento de resistência das culturas populares, que inclui a aproximação e apropriação do Estado e de conceitos acadêmicos por parte destas comunidades, como o próprio conceito de cultura popular. Partindo do protagonismo destas comunidades, proponho que a análise se dê com foco nas culturas populares, articulando com este conceito não apenas as manifestações simbólicas, mas também os sujeitos coletivos e seus territórios. Por fim, realizo uma análise crítica destas políticas culturais do MinC, pensando nas demandas e especificidades das culturas populares em contraste com as do mercado de bens culturais.
\end{abstract}

Palavras-chave: Cultura popular; Políticas culturais; Ministério da Cultura.

\section{Introdução}

As culturas populares têm sido, nos últimos anos, não apenas temas de discussões acadêmicas sobre tradição, identidade nacional e patrimônio, mas também público-alvo de políticas públicas nacionais, estaduais e municipais e tema de conferências internacionais. Paralelamente a esta inserção nos campos político e acadêmico, os próprios

\begin{abstract}
This paper approaches policies developed by the Ministry of Culture (MinC) between 2003 and 2010 (Gilberto Gil and Juca Ferreira offices) regarding popular culture. To achieve this aim, I will analyze the relationship between State, mainstream Social Science production and popular culture in Brazil, seeking to understand the process of selective appropriation of popular culture elements by a homogenizing State and reifying scientific narratives. I also assert that this process did not happened without a resistance movement from popular cultures, which includes the approximation and appropriation of concepts developed by the State and by Social Scientists by these communities, like the concept of popular culture itself. Having the central role of these communities as a starting point, I propose an analysis focusing on traditional popular culture communities, covering with this concept not only symbolic manifestations, but collective subjects and their territories. At last, I do a critical analysis of MinC's cultural policies, having in mind the contrast between the demands and specificities of popular cultures and those of cultural goods market.
\end{abstract}

Keywords: Popular culture; Cultural policies; Ministry of Culture.

sujeitos coletivos que são reconhecidos enquanto culturas populares (comunidades tradicionais, associações e grupos artísticos, entre outros) têm se organizado em associações comunitárias e religiosas, em redes e cooperativas, configurando-se como um grupo heterogêneo e ativo na demanda por reconhecimento e por recursos públicos. Assim, ainda que o rótulo de cultura popular tenha uma herança de margi-

${ }^{1}$ Mestrando do Programa de Pós-Graduação em Antropologia Social pela Universidade de Brasília (UNB), Brasil. E-mail: caio.csermak@gmail.com. 
nalização (pois o que é popular é reconhecido como aquilo que não é cultura erudita, alta cultura), vários sujeitos coletivos têm se apresentado e atuado politicamente a partir da apropriação do rótulo de cultura popular. Nesse sentido, Rita Segato (2005, p. 07, grifos no original) afirma que não foi dos grupos subalternos que "[...] partiu um desejo de diferença ou reconhecimento como valor, mas tornou-se valor como contradiscurso depois da experiência de rejeição e da constatação de que estrutura e outredade são coetâneas e que, portanto, para os sujeitos assim marcados, somente resta existir na gramática social como outredade". Segato (2005) alerta, no entanto, que esta outredade não significa que as identidades políticas são obrigatoriamente coincidentes com as alteridades históricas - isto é, a cultura popular enquanto identificação de sujeitos coletivos não significa a submissão destes à alteridade popular-erudito -, mas que uma matriz de identidades preexistentes formuladas nos centros formadores da linguagem pode ser eficiente na demanda por recursos e direitos. Para compreender esta dinâmica, defendo que é preciso olhar para a relação existente entre culturas populares, Estado e academia no Brasil, observando como as primeiras foram apropriadas seletivamente por um Estado homogeneizante e uma produção acadêmica reificadora. No entanto, é preciso notar que tal processo de apropriação homogeneizante e reificadora é parcial, uma vez que não são poucos os momentos de resistência das culturas populares a ele, bem como não poucos os momentos de ambiguidade nas ações e nos discursos da academia e do Estado.

Embora a discussão sobre políticas públicas para as culturas populares venha ganhando bastante importância no Brasil no âmbito do campo das políticas culturais, a reflexão, o desenho e a implementação de políticas públicas voltadas para a área é relativamente nova. Ainda que, já há mais de 50 anos, o folclore e a cultura popular sejam con- ceitos institucionalizados pelo Estado, em especial em decorrência do trabalho do grupo de estudiosos conhecido como folcloristas (VILHENA, 1997), a preocupação em formular e implementar políticas públicas que tratem as culturas populares como sujeitos coletivos de direitos - em lugar de objetos a serem inventariados, incentivados e preservados pelo poder público - é bastante recente, datando do início da gestão Gilberto Gil como Ministro da Cultura (MinC), em 2003. Foi somente a partir daí que as políticas públicas de âmbito federal passaram a preocupar-se com a dimensão de inclusão social e cidadã, possível a partir de políticas que buscassem o empoderamento dos sujeitos coletivos das culturas populares. Deste modo, a oferta de estudos que tratam do impacto destas políticas e que avaliem a formulação e implementação destas ainda é pequena, assim como os dados produzidos e disponibilizados pelo Governo Federal para o setor ainda são insatisfatórios. Desta maneira, apesar dos grandes avanços no discurso de gestores(as) do MinC e no desenho de algumas políticas públicas, como o Programa Cultura Viva, ainda é muito difícil avaliar se tais políticas realmente têm tido um impacto considerável no empoderamento das culturas populares ${ }^{2}$, no acesso destas a recursos públicos e na melhoria da qualidade de vida.

Neste artigo, busco contribuir para este debate, adotando como foco a discussão dos dados disponíveis no sentido de realizar uma análise qualitativa das políticas públicas do MinC voltadas para as culturas populares no período das gestões de Gilberto Gil e Juca Ferreira no Ministério da Cultura (2003-2010). Além disso, busco traçar em linhas gerais o contexto de produção cultural e de economia da cultura nos quais se inserem as manifestações artísticas ligadas às culturas populares. Por fim, pretendo fazer algumas proposições para as políticas públicas volta${ }^{2}$ A discussão sobre o conceito de culturas populares será feita mais adiante neste artigo. 
das às culturas populares no Brasil.

Na primeira parte do presente artigo, pretendo discutir a relação das culturas populares com o Estado brasileiro, valendo-me de algumas referências, por um lado, ao processo de uma apropriação seletiva das culturas populares pelo Estado como parte da formação de uma identidade nacional homogeneizante e, por outro, ao da luta dos sujeitos das culturas populares por espaço político, recursos simbólicos e materiais para a manutenção de suas tradições. Para isso, busco também inserir as culturas populares no contexto de economia da cultura no Brasil, de intenso crescimento e profissionalização do mercado de bens culturais. Na segunda parte, farei uma análise geral das políticas públicas do Ministério da Cultura (MinC) durante o período das gestões Gilberto Gil e Juca Ferreira (2003-2010). A intenção é lançar alguma luz sobre a compreensão de como as culturas populares brasileiras localizam-se em um contexto, nacional e internacional, no qual a cultura vem ganhando crescente importância no âmbito econômico, levando também em conta que governos e organizações internacionais, como a Organização das Nações Unidas para a Educação, a Ciência e a Cultura (UNESCO), passaram a ter a defesa e promoção da diversidade cultural como marcos legais e como orientação central no desenho de políticas de inclusão social e de promoção do desenvolvimento.

Antes, é necessário expor o que entendo por culturas populares. Para tanto, parto da definição proposta por Carvalho (2007, p. 81), a qual define culturas populares como

[...] um conjunto de formas culturais música, dança, autos dramáticos, poesia, artesanato, ciência sobre a saúde, formas rituais, tradições de espiritualidade -, que foram criadas, desenvolvidas e preservadas pelas comunidades, com relativa independência das instituições oficiais do Estado, ainda que estabelecendo com elas relações constantes de troca e delas recebendo algum apoio eventual ou parcial. As culturas populares distinguem-se também do que chamo de cultura popular comercial por não necessitarem dos implementos da indústria audiovisual, nem para sua concepção, nem para sua produção, nem para sua circulação no contexto em que foram criadas e em que são preservadas. Nesse sentido, pautam-se por um princípio de autonomia na frugalidade, na medida em que se reproduzem utilizando seus modestos recursos materiais e simbólicos e tomando em contra seus ritmos próprios de continuidade, mudanças e transformações. Em um nível diferente de abstração, podemos dizer que a auto-gestão e a auto-sustentabilidade comunitárias são os princípios que organizam a produção das culturas populares; e a oralidade é o seu meio predominante de expressão e transmissão.

A definição de Carvalho (2007) abrange a diversidade e complexidade que caracterizam as culturas populares no Brasil como um grupo marcadamente heterogêneo. Proponho, portanto, uma definição, que busca complementar a supracitada, buscando combinar tal abrangência com a preocupação de elaborar um conceito que possa ser operante no âmbito dos marcos legais do Estado. A saber: culturas populares são sujeitos coletivos indissociáveis de seus territórios (organizados em comunidades tradicionais ou grupos e/ou associações culturais) nas quais manifestações culturais (como música, dança, autos dramáticos, poesia, artesanato, ciência sobre a saúde, formas rituais, tradições de espiritualidade, sexualidade, culinária e técnicas de uso de recursos naturais) articulam-se de maneira íntima e indissociável de modos de vida que abarcam religiosidade, relações de parentesco, relações econômicas, concepções de natureza e território, organização comunitária, memória coletiva, línguas e métodos não institucionalizados de transmissão de saberes. Tais 
características são, a depender do caso, passíveis de classificação como patrimônios culturais imateriais nas modalidades previstas legalmente, como expressões culturais, saberes, celebrações e lugares. As culturas populares caracterizam-se por seu aspecto tradicional entendido aqui como preservação de uma memória coletiva viva, dinâmica e em constante transformação e contato com outros grupos e contextos sociais. Conformam-se, historicamente, como populações marginalizadas nos âmbitos social, geográfico, étnico-racial e de gênero, devendo as políticas públicas direcionadas a estes grupos articularem-se com outras políticas públicas de promoção da igualdade étnico-racial, social e de gênero previstas nos marcos legais nacionais e internacionais, assim como nos Planos Nacionais setoriais.

\section{Culturas populares, economia e estado}

Por muito tempo os estudos sobre desenvolvimento econômico e social ignoraram os aspectos culturais envolvidos no processo de busca por bem-estar econômico ou, quando não os ignoraram, pensaram que modelos de desenvolvimento econômico estariam atrelados a modelos culturais, notadamente ocidentais e anglo-eurocêntricos, nos quais predominam, por exemplo, o foco no indivíduo como sujeito político, o regime individual de propriedade e o domínio do ser humano sobre a nature$\mathrm{za}$; aspectos, muitas vezes, estranhos às culturas populares. Assim, o desenvolvimento não era visto como um meio para acessar recursos materiais a partir de um universo de culturas diversas, mas, sim, como certa concepção de cultura que seria mais eficiente para se atingir o desenvolvimento puramente material. Sabe-se que estudos com esta perspectiva ainda são comuns, mas, cada vez, fortificam-se perspectivas que colocam a própria cultura e a proteção e promoção da diversidade cultural como uns dos aspectos centrais do desenvolvimento.
Neste sentido, as convenções da Organização das Nações Unidas para a Educação, a Ciência e a Cultura (UNESCO) são um importante logro, pois ecoaram parte das demandas elaboradas pelas culturas populares e geraram marcos legais, políticos e teóricos ao colocar questões como diversidade cultural e cidadania como objetivos centrais do desenvolvimento, propondo que aspectos econômicos e culturais são complementares. Assim, a Convenção Sobre a Proteção e Promoção da Diversidade das Expressões Culturais da UNESCO, ocorrida em 2007 e da qual o Brasil é país signatário, afirma que "sendo a cultura um dos motores fundamentais do desenvolvimento, os aspectos culturais deste são tão importantes quanto os seus aspectos econômicos, e os indivíduos e povos têm o direito fundamental de dele participarem e se beneficiarem" (UNESCO, 2007). O conceito de desenvolvimento sustentável passa, então, a contemplar, além das questões ambientai, as questões culturais. O texto da Convenção afirma que "a diversidade cultural constitui grande riqueza para os indivíduos e as sociedades. A proteção, promoção e manutenção da diversidade cultural é condição essencial para o desenvolvimento sustentável em benefício das gerações atuais e futuras" (UNESCO, 2007). Deste modo, políticas públicas que objetivam o desenvolvimento e a inclusão social e cidadã, mas que não levam em conta as dimensões culturais do desenvolvimento, estarão fadadas a serem contraproducentes, pois são os próprios Estados, como signatários da Convenção da UNESCO, que reconhecem a complementaridade entre as dimensões econômica e cultural, gerando, assim, um marco legal para que as culturas populares lutem por reconhecimento, recursos e políticas públicas específicas para o setor.

O Brasil, que teve ativa participação na confecção do texto da Convenção supracitada, tem paulatinamente agregado esta visão à suas políticas 
públicas, pelo menos na dimensão discursiva. Se as políticas públicas estão realmente sendo executadas e implementadas com esta perspectiva, é outra questão a ser discutida. Por isso, estudos críticos e de avaliação de políticas públicas são tão importantes: ainda que presentes no discurso governamental e no desenho das políticas públicas, muitos direitos garantidos por marcos legais nacionais e internacionais não são colocados em prática por uma série de empecilhos, como rigidez institucional, corrupção, falta de vontade política e restrições e contigenciamentos orçamentários. No caso do Ministério da Cultura (MinC), a dimensão cultural do desenvolvimento passou a ser uma preocupação central a partir da gestão Gilberto Gil. Nesta perspectiva, Ranulfo Alfredo Manevy (2007, p. 56), ex-titular da Secretaria de Políticas Culturais do MinC, afirmou que "a premissa desta Secretaria - que está em sintonia com a premissa do Ministério da Cultura nesta gestão - é de que a cultura deve migrar para o centro do nosso projeto de desenvolvimento". Já nas palavras do próprio ex-ministro Gilberto Gil (2007, p. 29):

O Brasil é um dos países com a maior diversidade cultural do mundo. Cabe ao Estado brasileiro trabalhar para que esta diversidade seja uma realidade cada vez mais presente, para que as diversas manifestações culturais do país tenham condições de preservar e inovar suas criações.

Sérgio Mamberti (2005, p. 119), outro ex-gestor do MinC, que comandou a Secretaria da Identidade e da Diversidade Cultural, afirma que "por meio de editais de fomento às expressões das culturas populares, [...] queremos dar melhores condições para que os artistas das culturas populares sejam sujeitos das políticas culturais". Assim, creio que o MinC deu um importante passo no sentido de agregar a dimensão cultural às políticas voltadas para $o$ desenvolvimento, o que foi muito im- portante para empoderar e incluir socialmente as culturas populares. Neste contexto, a cultura coloca-se como um recurso de luta política por cidadania e justiça social. Como afirma George Yúdice $(2004$, p. 25), “[...] a cultura está sendo crescentemente dirigida como um recurso para a melhoria sociopolítica e econômica, ou seja, para aumentar sua participação nesta era de envolvimento político decadente, de conflitos acerca da cidadania [...]". Tal perspectiva é essencial no caso das culturas populares, historicamente ligadas a grupos social, étnica e racialmente marginalizados no Brasil, e que hoje lutam politicamente por recursos, visibilidade e cidadania a partir do uso da cultura como um recurso e do acesso a marcos legais de defesa e promoção da diversidade cultural.

Outro conceito que vem ganhando espaço nas análises sobre políticas culturais é o de economia da cultura, também chamado de economia criativa, que pretende dar conta do estreito entrelaçamento entre as esferas cultural e econômica. Assim, a cultura é cada vez mais um campo de geração de riquezas e de potencialidade de novos investimentos, especialmente com o avanço das tecnologias que desmaterializam as cadeias produtivas e distributivas, permitindo que o comércio de bens culturais ocorra de modo rápido e amplo. Segundo Elder Alves (2011a, p. 302):

[...] a economia da cultura é o setor da economia mundial que mais cresce, que mais agrega valor a uma cadeia de marcas e produtos, que mais exporta e melhor remunera, e que menos impacta o meio ambiente e seus recursos esgotáveis, pois está secundada na capacidade criativa e nas formas de apreciação e consumo do intangível

Representando esta afirmação em alguns dados numéricos, Paula Porta (2008) afirma que: 
O Banco Mundial estima que a Economia da Cultura responda por $7 \%$ do PIB mundial (2003). Nos EUA a cultura é responsável por $7,7 \%$ do PIB, por $4 \%$ da força de trabalho e os produtos culturais são o principal item de exportação do país (2001). Na Inglaterra, corresponde a $8,2 \%$ do PIB (2004), emprega $6,4 \%$ da força de trabalho e cresce $8 \%$ ao ano desde 1997 .

Desta forma, a Economia da Cultura representa uma fatia de $7 \%$ do PIB mundial, o que é muito significativo para qualquer atividade econômica. No caso brasileiro, Porta (2008) afirma que "atuam no país 320 mil empresas voltadas à produção cultural, que geram 1,6 milhão de empregos formais. Ou seja, as empresas da cultura representam $5,7 \%$ do total de empresas no país e são responsáveis por $4 \%$ dos postos de trabalho". Com relação ao percentual do PIB brasileiro representado pelo setor cultural, Elder Alves afirma que, no ano de 2003, este número chegou a 4\% (ALVES, 2011a). Isto é, mesmo que no Brasil a participação do setor cultural na economia ainda seja cerca de metade da de países como EUA e Inglaterra e ainda seja consideravelmente menor do que a média mundial, não há como negar que a economia da cultura representa um percentual importante das riquezas produzidas no país e que representa um percentual significativo da força de trabalho. Somado a isto, a perspectiva de crescimento para a área a coloca como uma política estratégica para o país, não só enquanto promotora de inclusão social e cidadã, mas também enquanto atividade geradora de crescimento econômico e de postos de trabalho. Em outras palavras, o entrelace dos âmbitos cultural e econômico e seu potencial, tanto de geração de riqueza como de transformação social, faz com que as políticas culturais sejam um setor estratégico para qualquer governo que busque políticas de crescimento econômico aliadas ao desenvolvimento sustentável.
A cultura, portanto, também passou a ser entendida como investimento com alto potencial de retorno econômico. Por isso, é importante ressaltar que, ao falarmos de cultura ou, no caso, de economia de cultura, estamos também falando de um mercado de produção e consumo de bens culturais. Este mercado, no Brasil, especialmente desde a criação das leis de incentivo à cultura, como a Lei do Audiovisual (Lei Federal $\mathrm{n}^{\circ} 8.695 / 93$ ) e a Lei Rouanet (Lei Federal $\mathrm{n}^{\circ} 8.313 / 91$ ), está completamente entrelaçado com os recursos públicos obtidos via renúncia fiscal. Cabe, assim, perguntar: como incluir culturas populares, historicamente marginalizadas, em um contexto de crescente profissionalização do setor cultural? Como fazer com que as políticas culturais levem em conta as especificidades destas comunidades sem deixar de incluí-las nos ganhos materiais gerados pelo setor cultural? Como repensar a relação entre culturas populares e Estado, historicamente marcada no Brasil por uma apropriação seletiva, por parte do Estado, das culturas populares enquanto setores marginais que compõem uma narrativa homogeneizante de nação através de um discurso de mestiçagem? São estas perguntas que guiam minhas preocupações neste artigo. Certamente não cabe no escopo deste trabalho dar respostas completas a elas, mas o essencial é salientar que estas indagações colocam algumas questões centrais do debate atual sobre cultura popular no Brasil.

A primeira questão que creio ser central para as perguntas levantadas é a ambiguidade da histórica relação entre culturas populares e o Estado no Brasil; relação que sempre esteve na fronteira entre apropriação seletiva e marginalização. Sobre este tema, Rita Segato refere-se ao processo de que, no seio da construção da nação, ocorrer a criação de um outro interior, anexado simbolicamente pelas elites. Segundo Segato (2005, p. 07): 
O processo de produção de alteridades como resultado da entronização de um grupo no controle das instituições chamadas "estatais" não significa que elementos do repertório de cultura característicos daquelas identidades subalternizadas não sejam, frequentemente, apropriados pelos grupos que se confundem com a administração estatal e com a nação em si. [...] Trata-se de um franco "direito de pernada" simbólico, de um sequestro e apropriação simbólica nem sempre consentida para "nacionalizar", no sentido de "expropriar", os ícones de cultura dos grupos sob o domínio da sua administração. As elites se etnicizam e folclorizam para incluir na sua heráldica os símbolos dos territórios apropriados

Neste sentido, creio que é possível afirmar que aquilo que chamo de apropriação seletiva das culturas populares por parte do Estado na construção de uma noção, ao mesmo tempo plural e homogênea, de nação é também um processo de territorialização destes grupos que habitam as margens do Estado. Para Deleuze e Guatarri (1997, p. 23):

[...] o Estado ele mesmo sempre esteve em relação com um fora, e não é pensável independentemente desta relação. A lei do Estado não é a lei do Tudo ou Nada [...], mas a do interior e a do exterior. O Estado é soberania. No entanto, a soberania só reina sobre aquilo que ela é capaz de interiorizar, a de apropriar-se localmente.

Assim, o "outro interior", a que se refere Segato, torna-se, nesta perspectiva, aquilo que é externo ao Estado, "[...] os mecanismos locais de bandos, margens, minorias, que continuam a afirmar os direitos de sociedades segmentárias contra os órgãos de poder do Estado" (DELEUZE; GUATTARI, 1997, p. 23). São estes grupos que o Estado e as elites que o compõem tentam domesticar a partir de uma apropriação simbólica que os reifica e que tem con- sequências materiais para estes grupos. Como afirmam Veena Das e Deborah Poole (2004, p. 09), "[...] so much of the modern state is constructed through its writing practices. We recognize that the documentary and statistics-gathering practices of the state are all intended, in some sense, to consolidate state control over subjects, populations, territories and lives". Por este viés, as políticas públicas e a produção de dados oficiais podem ter o efeito de apropriação de grupos marginais pelo Estado, incluindo-os virtualmente em um projeto nacional excludente nos âmbitos simbólico e material. Tal apropriação dá-se no sentido de um maior controle do Estado sobre grupos populacionais específicos.

Para Deleuze e Guattari, no entanto, tal processo de apropriação das margens pelo Estado é caracterizado como uma territorialização que tenta, sem sucesso, ser total, pois o poder sempre age contra uma resistência. Tal resistência cria linhas de fuga que o poder de territorialização do Estado não consegue controlar completamente: as margens, portanto, podem ser apropriadas por um poder central, porém, tal processo é limitado, já que as margens têm sua própria agência e sempre escapam pelos vãos dos dedos. Deste modo, a tentativa de fixar aspectos simbólicos das culturas populares como narrativas estáticas e homogeneizantes de nação (no caso brasileiro, a partir de um discurso da mestiçagem que tenta domesticar a heterogeneidade e o conflito do processo de construção da nação) nunca consegue fixar completamente estes grupos, nunca consegue conter o movimento que os caracteriza. Assim, tais grupos usaram estrategicamente muitos conceitos fixados no que Deleuze e Guattari chamam de ciência régia ${ }^{3}$ (como tradição, autenticidade e cultura popular) e deles apropriaram sem, contudo, deixarem-se fixar por tais conceitos. Estou ciente de que esta

${ }_{3}^{3}$ Para Deleuze e Guatarri (2007), a ciência régia é aquela ciência ligada ao Estado, legal, formal, cômpar e que tenta capturar o movimento em conceitos estáticos 
afirmação não se estende a todos os sujeitos coletivos das culturas populares, porém muitos deles se percebem hoje como grupos de resistência frente a um Estado e a uma elite que historicamente os marginalizaram e objetificaram. Neste caso, resistir significa também lutar para acessar o Estado (SEGATO, 2005). Portanto, enquanto o Estado e a ciência régia dotaram de rigidez as categorias de autenticidade, tradição e cultura popular, as culturas populares (e nisso está incluso a própria adoção por parte de muitas comunidades do rótulo de cultura popular) apropriaram-se destes conceitos para demandar políticas públicas frente ao Estado, ou seja, para demandar reconhecimento frente a uma elite intelectual que se apropriou de suas referências simbólicas sem deixar de subordiná-las às referências da alta cultura. Como afirma Bruno Latour (2005), a ciência também faz o mundo, não apenas o descobre. Assim, quando as ciências sociais criaram o conceito de cultura popular em contraponto ao que seria a alta cultura (ou cultura erudita), também criaram uma categoria com a qual sujeitos coletivos periféricos se identificaram, passando elas próprias a se apresentarem como tal.

Em contraponto ao que chamam de ciência régia, Deleuze e Guattari (1997) propõem a existência da ciência nômade, ambulante, díspar, não legalista, heterogênea e que segue o fluxo da matéria. Sendo cômpar, a ciência régia busca a regularidade, as constantes tomadas a partir das variáveis; sendo díspar, a ciência nômade busca colocar as próprias variáveis em estado de variação contínua. No entanto, mesmo que opostas entre si, estes dois tipos de ciência relacionam-se de modo muito íntimo. Segundo os autores:

Estamos diante de duas concepções de ciência, formalmente diferentes; e, ontologicamente, diante de um só e mesmo campo de interação onde uma ciência régia não para de apropriar-se dos conteúdos de uma ciência nômade ou vaga, e onde uma ciência nômade não para de fazer fugir os conteúdos da ciência régia (DELEUZE; GUATTARI, 1997, p. 34).

A partir desta divisão, creio ser possível afirmar que os aspectos simbólicos das culturas populares (aqui compreendidas como representantes de uma ciência nômade) foram apropriados, no Brasil, no decorrer do século XX, pelo Estado e pelas elites intelectual, social e econômica (compreendidos como representantes de uma ciência régia) no sentido de construir uma narrativa estática e homogeneizante de nação. Nesta narrativa, o apelo à retórica da mestiçagem entre brancos(as), negros(as) e indígenas resultou no mito das três raças e da democracia racial, no sentido de construir a imagem de uma cultura que, ainda que plural, resultasse em um amálgama com o qual todos(as) os(as) brasileiros(as) se identificariam, invisibilizando a violência, o conflito e o dissenso do processo (GUIMARÃES, 2002). Neste sentido, Bruno Latour (2005, p. 162) afirma que "[...] the body politic was supposed, by construction, to be virtual, total, and always already there. There is not wrong with this since it had to solve the impossible problem of political representation, fusing the many into one and making the one obeyed by the many". Por isso, esta inclusão de aspectos simbólicos das culturas populares em uma narrativa oficial de nação não significa que estas estejam sendo representadas por esta narrativa homogeneizante, uma vez que esta funde a heterogeneidade e o conflito da construção da nação brasileira em um discurso de mestiçagem no qual as margens do Estado não se reconhecem. Também por este motivo parte do processo de resistência destas margens do Estado é recontar a história da nação a partir de sua perspectiva, do conflito e do não enquadramento nos discursos hegemônicos. Com relação a esta ques- 
tão, Michael Herzfeld (1997, p. 02) afirma que o Estado:

[...] converts revolution into conformity, represents ethnic cleansing as national consensus and cultural homogeneity, and recasts the sordid terrors of emergence into a seductive immorality. Because it is grounded in an idiom of social immediacy, however, this historical streamlining never quite succeeds in concealing a residual sense of contradiction. That sense may provide opportunities for critique, and eternal truths can have surprisingly short lives.

Esta narrativa homogeneizante sobre a nação promovida pelo Estado, portanto, nunca é completamente estática, ainda que assim se pretenda. Além disso, transforma-se com o processo histórico e com a resistência daqueles grupos que não se sentem representados por ela. Assim, ainda que o Estado queira fixar e essencializar identidades e grupos sociais, ele mesmo se afeta neste processo, pois a reificação deixa sempre um resíduo de ambiguidade. Neste sentido, Herzfeld (1997, p. 21 , grifos no original) afirma que "this adherence to a static cultural ideal has a surprising and presumably consequence: not only does it ground certain permissible forms of debate but it also permits and perhaps even encourages the day-to-day subversion of norms". Deste modo, muitas narrativas concorrentes são contadas, explorando umas as contradições das outras, e mesmo o próprio Estado é heterogêneo e carrega em si suas próprias contradições e seus conflitos, pois como afirmam Deleuze e Guattari (1997, p. 41), o poder sempre permite linhas de fuga. Para eles:

Há sempre uma corrente graças a qual as ciências ambulantes ou itinerantes não se deixam interiorizar completamente nas ciências régias reprodutoras. E há um tipo de cientista ambulante que os cientistas de Estado não param de combater, ou de integrar, ou de aliar-se a ele sob a condição de lhe proporem um lugar menor no sistema legal da ciência e da técnica.

Desta forma, os saberes tradicionais ganham um lugar marginal com relação aos saberes régios legitimados pelo Estado (como na deslegitimação do saber das parteiras em detrimento dos(as) obstetras, por exemplo) e, ainda que apropriados seletivamente como parte da narrativa da nação, não chegam a serem reconhecidos enquanto saberes legítimos. Além disso, não raramente, seu uso é perseguido pelos órgãos reguladores do Estado. Assim, no campo de interação entre as duas ciências, os saberes tradicionais podem ser reconhecidos como patrimônio imaterial, como tradição autêntica e imemorial, como influência autóctone para as vanguardas artísticas; porém na condição de objetos da ciência régia, em vez de na condição de sujeitos produtores de conhecimento legítimo.

Quanto a isso, Deleuze e Guattari (1997, p. 42) afirmam que:

No campo de interação das duas ciências, as ciências ambulantes contentam-se em inventar problemas, cuja solução remeteria a todo um conjunto de atividades coletivas e não científicas, mas cuja solução científica depende, ao contrário, da ciência régia, e da maneira pela qual esta ciência de início transformou o problema [...].

Creio, portanto, que parte do processo de deslegitimação dos saberes tradicionais se dá por este processo de captura feito pela ciência régia, que retira tais saberes do contexto em que são produzidos, nos quais estão envolvidos aspectos de religiosidade, parentesco, relação com o território e com os ciclos da natureza, manifestações artísticas etc. Por isso, este movimento de deslocamento de tais saberes das margens do Estado para a narrativa da nação e do patrimônio imaterial coletivo é também um processo de desterritorialização das 
culturas populares decorrente da característica de dominação e regulação do Estado.

As culturas populares são, portanto, grupos marginalizados que até hoje obtêm pouco reconhecimento de instâncias culturais hegemônicas. Neste sentido, não se trata apenas do Estado, que historicamente se apropriou seletivamente de expressões da cultura popular para construir politicamente um sentido de identidade nacional sem, com isso, dar condições de autonomia e cidadania para estes grupos, mas também de elites artísticas que se apropriaram de suas manifestações simbólicas sem deixar de ovacionar a alta cultura letrada e erudita. Trata-se também do saber acadêmico, que teve nas culturas populares um objeto de conhecimento e de inventariação sem, contudo, trazer os saberes populares para dentro das fronteiras da academia enquanto sujeitos produtores de conhecimento. Isso implica que falar em marginalização e invisibilização das culturas populares não quer dizer que Estado, elites econômica e artística e academia não se interessavam ou se relacionavam com estes grupos, mas, sim, que foram historicamente destituídos da condição de sujeitos, sendo tratados como objetos pelas instituições hegemônicas.

É esta realidade que deve ser transformada para que ocorra uma inclusão social e cidadã das culturas populares por meio da demanda de políticas públicas junto ao Estado. Como afirma Herzfeld, o Estado captura e é capturado por aqueles que objetifica (HERZFELD, 1997). Portanto, abordar as culturas populares enquanto forma de resistência frente a um Estado que as objetifica e marginaliza não quer dizer que esta luta é necessariamente contra o Estado, mas que é também uma luta por acesso ao Estado, por acesso a direitos, recursos e políticas públicas que foram historicamente concentrados nas mãos das elites, especialmente no que se trata das políticas culturais, que ainda são, no
Brasil, e já foram ainda mais, privilégio das elites artísticas e dos(as) produtores(as) profissionais da alta cultura.

A resistência a qual me refiro aqui se estabelece em um círculo que Herzfeld chama de intimidade cultural, a qual, ainda que não tenha uma fronteira fixa, faz com que também os grupos que habitam as margens do Estado sintam-se, em alguma medida, parte de uma sociabilidade comum, identifiquem-se em alguma medida com uma narrativa de nação e também capturem e objetifiquem o Estado (HERZFELD, 1997, grifos no original). Para o autor:

[...] social life consists of processes of reification and essentialism as well as challenges to these processes. This is the corollary to recognizing the strategic character of essentialism. Distrust of essentialism in social theory should not blur our awareness of its equally pervasive presence in social life. Essentializing essentialism is pointless (HERZFELD, 1997, p. 26).

Não são apenas o Estado e as narrativas hegemônicas que essencializam identidades e grupos sociais, mas todas as pessoas em todos os lugares. Ainda segundo Herzfeld (1997, p. 24):

The state is caught on the horns of its own reification. To achieve at least an illusion of stability it must command the active involvement of ordinary people; and ordinary people reify, all the time, everywhere. They too invoke solidified histories, rediscovering in the official mythology some aspects that will serve their own cause.

Assim, as culturas populares também reificam em seu cotidiano, também entendem suas próprias manifestações artísticas e modos de vida enquanto tradições autênticas, enquanto patrimônios imateriais coletivos, enquanto representantes legítimos da cultura brasileira e usam também destas percepções acerca de si para fazerem suas demandas ao 
Estado. Por este motivo também buscam conseguir que o Estado atenda às suas demandas mantendo uma relação que é, ao mesmo tempo, de resistência e intimidade, criando amizades políticas, recebendo recursos de instâncias administrativas e agradecendo figuras públicas em seus discursos. Como afirmam Veena Das e Deborah Poole, o Estado não se constrói apenas em oposição às margens, mas também as englobando e sendo constituído por elas (DAS; POOLE, 2004).

As autoras afirmam, ainda, que as populações nas margens do Estado são patologizadas através de várias práticas de poder e conhecimento, mas que, contudo, não se submetem passivamente a estas condições (DAS; POOLE, 2004). Isso não significa que qualquer prática cotidiana das populações marginais terá o significado de resistência, mas, sim, que as fronteiras do Estado vão sendo estendidas e refeitas no processo de sobrevivência e luta por justiça destas comunidades e que a própria característica heterogênea e indeterminada destas margens quebra a solidez geralmente atribuída ao Estado, permitindo formas de resistência que, muitas vezes, se traduzem em um maior engajamento do Estado com estas margens (DAS; POOLE, 2004). A questão, portanto, é a de que a relação das margens com o Estado é ambígua e a de que o próprio processo de resistência muitas vezes se dá em termos de aproximação e reformulação do Estado, uma vez que o acesso destes grupos às instâncias e aos recursos estatais ainda é demasiadamente desigual e marginal.

Desta forma, políticas públicas voltadas para as culturas populares não podem tratá-las enquanto produtores(as) culturais profissionais, justamente porque são estes(as) que historicamente têm acesso aos recursos públicos, aos equipamentos culturais e aos editais oriundos das leis de incentivo. Faz-se necessário esclarecer que, com um desenho de políticas públicas que demanda alta profissionalização dos(as) produtores(as) culturais, não exis- te igualdade de acesso às políticas e aos recursos públicos, pois é também em relação a este processo de industrialização da cultura que os grupos de cultura popular tradicional estão marginalizados. Como afirma Maria Laura Viveiros de Castro Cavalcanti (2005, p. 32):

Um músico erudito que compõe para a maravilhosa rabeca e um rabequista popular, lavrador, que toca junto com toda a família suas composições, podem ter suas músicas gravadas num $\mathrm{CD}$ de divulgação nacional e mesmo internacional. Esses dois artistas têm muito a dizer um ao outro, mas o apoio de que necessitam é muito diferenciado. Certamente, e este é o ponto central da discussão, muitos produtores diretos da cultura popular carecem de apoio e amparo de modo muito mais agudo do que os produtores de cultura inscritos em outros circuitos da produção cultural. Precisam da valorização de sua cultura, sim. Vale notar, porém, que não necessariamente da valorização de sua cultura como a mais genuína. A questão crítica é o acesso aos direitos básicos de cidadania - moradia, educação, saúde - em recantos onde a presença do Estado é, muitas vezes, ainda precária. A inclusão social é um desafio para nossa democracia.

De acordo com a autora, as culturas populares necessitam de políticas públicas que as tratem de modo diferenciado, de ações afirmativas que visem garantir igualdade no acesso a recursos que têm um histórico de desigualdades e privilégios neste acesso. Um exemplo desta desigualdade é o histórico da Lei Rouanet, cujos projetos que conseguem captar recursos são, em sua maioria, grandes projetos do Sudeste do Brasil que têm apelo junto às grandes empresas (ALVES, 2011a). As empresas, por sua vez, financiarão projetos com os quais querem ver atreladas as suas marcas, pois se trata de uma ação de marketing cultural. Considerando que as culturas populares são grupos social, étnica e 
racialmente marginalizados, é esperado que não consigam financiamento junto a estas empresas, que querem suas marcas atreladas a projetos que visam ao grande público. Além disso, existem outros empecilhos ao acesso de recursos por parte de grupos e culturas populares, como a dificuldade técnica de elaborar projetos no modelo do MinC, problemas para cumprir com os procedimentos burocráticos, especialmente $\mathrm{o}$ processo de prestação de contas, entre outros. Deste modo, é papel do Estado o desenvolvimento de políticas públicas e ações afirmativas que busquem corrigir a imensa desigualdade no acesso aos recursos públicos. Como coloca Marco Acco (2007, p. 64), "é inconcebível tratar um artista ou um produtor cultural que exporta sua produção e detém milhões de reais em sua conta, da mesma forma que se trata as comunidades indígenas que não têm como receber recursos, pois que supostamente não tinham CNPJ". Quanto a isto, também acredito que a análise antropológica sobre as culturas populares não deve se limitar a questões de cunho simbólico; deve focar também os aspectos materiais que afetam estes grupos e pensar como estas duas dimensões estão imbricadas entre si. Como afirma Herzfeld (1997), o binarismo que separa a Antropologia enquanto moralidade e enquanto ciência é pernicioso e cartesiano, pois a atividade simbólica é relevante para a análise material. Neste artigo, portanto, tento estabelecer uma ponte entre a dimensão simbólica das culturas populares e os aspectos materiais que permeiam a demanda destas por direitos, recursos e políticas públicas frente ao Estado, argumentando que também os(as) gestores(as) públicos(as) devem ter sensibilidade para as questões simbólicas envolvidas no processo de elaboração de políticas públicas, pensando que estas terão consequências tanto simbólicas quanto materiais para os grupos que as acessam.

Nesta perspectiva, as manifestações artísticas das culturas populares também não podem ser tratadas como um modo de produção cultural corriqueiro, pois estão ligadas a modos de vida e de organização comunitária distintos da lógica de mercado que caracteriza a produção cultural profissional. As manifestações artísticas das culturas populares são apenas uma face da vida das comunidades e estão integradas com uma série de outros âmbitos, como o parentesco, a religiosidade, a história da comunidade, a história de seus objetos e entidades sagrados, o pertencimento a determinado território, a identidade étnica e racial, entre outros. Assim, se esta vem descolada de todo o resto do modo de vida que produziu tal manifestação, não basta dar visibilidade a uma manifestação artística, focando apenas a sua dimensão estética. Neste sentido, José Jorge de Carvalho (2005, p. 35) afirma que:

Desde as mudanças que ocorreram na década de 70 e 80 , a sociedade passou por grandes mudanças. Houve uma ênfase na estética e a principal discussão foi sobre as formas de cultura, em geral. Neste processo, houve um fascínio pela cultura popular, pela estética dessa cultura, de forma que se geraram três vácuos: o social, o econômico e o racial. Assim, deixou-se de lado a análise das culturas populares como lugar de luta de classe, ou mesmo do lado mais espiritual, para se discutir o lado estético e econômico. É importante, portanto, que todos estes aspectos sejam contemplados simultaneamente pelas políticas públicas voltadas para as culturas populares.

A falta de sensibilidade de políticas públicas para tratar as culturas populares enquanto um todo que integra variadas dimensões da vida comunitária gera o que José Jorge de Carvalho chama de espetacularização das culturas populares. Segundo Carvalho (2007, p. 83), a espetacularização é uma:

[...] operação típica da sociedade de massas, em que um evento, em geral 
de caráter ritual ou artístico, criado para atender a uma necessidade expressiva específica de um grupo e preservado e transmitido através de um circuito próprio, é transformado em espetáculo para consumo de outro grupo, desvinculado da comunidade de origem.

O autor afirma, ainda, que:

A espetacularização é um processo multidimensional. [...] Trata-se de enquadrar, pela via da forma, um processo cultural que possui sua lógica própria, cara aos sujeitos que a produzem, mas que agora terá seu sentido geral redirigido para fins de entreter um sujeito consumidor dissociado do processo criador daquela tradição (CARVALHO, 2007, p. 84).

Assim, a mera entrada das culturas populares em um circuito profissionalizado de produção cultural não garante que alas estejam ganhando autonomia e sendo incluídas socialmente. É preciso que as próprias comunidades tenham voz para também influenciarem o processo de inclusão cidadã de acordo com as suas próprias necessidades e de acordo com o significado local de suas manifestações artísticas. Neste sentido, pode ser importante que uma manifestação artística ligada às culturas populares ganhe visibilidade a partir da participação em um festival. Contudo, acreditar que isso é o suficiente para gerar autonomia e inclusão social é ignorar completamente que tal manifestação está conectada a um modo de vida específico, a uma concepção de ritual e religiosidade que pode não ir, e em geral não vai, em direção ao modelo de espetáculo gerenciado pelo circuito de produção cultural profissional. É este tipo de sensibilidade que as políticas culturais devem ter, para que, além do fomento ao crescimento econômico do setor de produção cultural, realizem de modo efetivo a proteção e promoção da diversidade cultural que norteia o traba- lho do MinC e as convenções da UNES$\mathrm{CO}$ das quais o Brasil é signatário.

\section{$3 \mathrm{O}$ MinC e as culturas populares: narrativas e políticas}

Durante a gestão de Francisco Weffort no Ministério da Cultura (MinC), nos governos de Fernando Henrique Cardoso, a tônica das políticas culturais foram as leis de incentivo fiscal, em especial a Lei Rouanet, que foi responsável pela alocação da maior parte dos recursos do MinC no período. Como os editais não se pautavam por temas e áreas específicas e como o processo de captação dos recursos aprovados dependia da vontade das empresas que usariam o mecanismo de renúncia fiscal, as culturas populares foram, mais uma vez, sistematicamente excluídas dos mecanismos de financiamento das políticas culturais em âmbito federal (BARBALHO, 2007; RUBIM, 2007). É somente a partir da gestão de Gilberto Gil na pasta, já no começo do governo Lula em 2003, que o MinC passou a se preocupar diretamente em desenhar políticas voltadas para setores que não eram contemplados pelo sistema de leis de incentivo, ainda que o modelo de políticas baseado nas leis de incentivo continue a operar de modo relevante até hoje. A gestão de Gil começa com a proposição de um papel mais relevante do Estado no setor de cultura. Assim, ainda que não abandone o modelo da renúncia fiscal, o MinC busca fortalecer o Fundo Nacional de Cultura (FNC), mecanismo já existente na Lei Roaunet de descentralização de recursos públicos via convênio (RUBIM, 2007). Além disso, a gestão de Gil na pasta busca ampliar o conceito de cultura operacionalizado pelo Estado, passando de um conceito de cultura enquanto negócio para uma percepção "antropológica" de cultura, mais ampla e que inclui não apenas os produtos culturais finais, mas também os processos e os modos de vida envolvidos na produção destes (BARBA- 
LHO, 2007). Tal mudança no discurso oficial sobre a cultura vai ao encontro de uma nova ordem discursiva internacional - sobretudo no âmbito da UNES$\mathrm{CO}$ - na qual a diversidade cultural e o direito à diferença ganharam força, como discutirei mais à frente.

A gestão de Gil busca também maior participação política da sociedade civil na definição das diretrizes das políticas a serem elaboradas pelo MinC. Assim, no bojo das conferências nacionais realizadas a partir do início do governo Lula, em 2005, foi realizada a $1^{\text {a }}$ Conferência Nacional de Cultura (CNC), a qual foi precedida por conferências municipais e estaduais. Da CNC saíram as diretrizes que viriam a embasar a elaboração do Plano Nacional de Cultura (PNC), instituído pela Lei $\mathrm{n}^{\mathrm{o}} 12.343$, de 02 de dezembro de 2012. Além da $\mathrm{CNC}$, para a elaboração do PNC também contribuíram os planos setoriais do MinC, estudos do Instituto de Pesquisa Econômica Aplicada (IPEA), o Suplemento de Cultura da Pesquisa de Informações Básicas Municipais (MUNIC), elaborado pelo Instituto Brasileiro de Geografia e Estatística (IBGE), e os documentos dos encontros do seminário Cultura para Todos, realizados em 2003 (RUBIM, 2008a). Rubim (2008b) afirma que, ainda que a discussão sobre o PNC tenha começado em 2000, é a partir da gestão de Gilberto Gil que este se torna um compromisso.

O PNC estipula que o Estado deve atuar como indutor, fomentador e regulador do setor de cultura com o intuito de incentivar, proteger e promover a diversidade cultural brasileira e de ampliar a participação da cultura na promoção do desenvolvimento econômico sustentável e da participação social na elaboração e gestão de políticas culturais (BRASIL, 2010). Dentre as dezenas de estratégias e ações do PNC, as culturas populares constam em três: a) o estabelecimento de abordagens intersetoriais e interdisciplinares para a execução de políticas para as culturas populares, prevendo a inclusão de seus detentores neste processo, b) a criação de políticas de transmissões de saberes e fazeres das culturas populares, incluindo o reconhecimento formal dos mestres tradicionais e mecanismos de apoio para estes e c) o estímulo à criação de centros de referência e comunitários voltados às culturas populares (BRASIL, 2010).

O PNC faz parte de um processo maior de estruturação e institucionalização do campo da cultura, que resultou na construção do Sistema Nacional de Cultura (SNC) (CALABRE, 2009), que, dentre vários outros objetivos, buscar coordenar nacionalmente as políticas culturais nos âmbitos federal, estaduais e municipais, sendo operacionalizado através da adesão de estados e municípios. A partir da adesão, o MinC fornece apoio técnico para os municípios e estados para a elaboração e gestão das políticas culturais. Em contrapartida, estados e municípios devem implementar uma secretaria de cultura, um conselho de política cultural, uma conferência periódica de cultura, um plano de cultura e um fundo de cultura. Os estados devem, ainda, constituir uma comissão intergestora. O SNC, contudo, ainda está em fase de implementação ${ }^{4}$. Por fim, com o objetivo de produzir e disponibilizar informações e estatísticas sobre o setor de cultura no Brasil, o MinC criou o Sistema Nacional de Informações e Indicadores Culturais (SNIIC), o qual funciona também como a plataforma de monitoramento do PNC (BRASIL, 2010). O SNIIC ainda não está totalmente implementado.

É também somente a partir da gestão de Gilberto Gil na pasta que o MinC passou a se preocupar diretamente em desenhar políticas voltadas para setores que não eram contemplados pelo sistema de leis de incentivo e pela inoperância do FNC. Um exemplo disto é o caso de políticas voltadas para as culturas populares, nas quais o MinC passou a ${ }_{4}^{4}$ Disponível em <http://www.brasil.gov.br/sobre/cultura/iniciativas>.
Acesso em 15 jul. 2013 . 
se apropriar da visão de que o setor era essencial para a proteção e promoção da diversidade cultural e necessitava de políticas diferenciadas, já que ficava às margens do processo profissionalizado e viciado das leis de incentivo. São justamente os setores marginalizados, como as culturas populares, que são os que mais são prejudicados pelo sistema de terceirização das decisões públicas para o setor privado, pois estes grupos, geralmente, estão poucos inseridos nos mercados formais da produção cultural e dependem de políticas públicas para que tenham condições de acesso mais justas aos recursos públicos.

Como afirma Ranulfo Manevy (2007), ex-Secretário de Políticas Culturais do MinC, o objetivo da gestão Gilberto Gil, ao tomar posse da pasta, foi fazer da cultura um eixo estratégico do modelo de desenvolvimento buscado pelo governo Lula. Deste modo, mesmo que os mecanismos de editais de leis de incentivo ainda sejam uma importante política do MinC, a partir de 2003 a pasta começou a elaborar uma série de políticas a serem implementadas diretamente pelo MinC, priorizando o FNC em detrimento aos mecanismos de incentivo fiscal e mantendo o poder decisório do MinC sobre os recursos públicos. Neste contexto, encaixam-se as políticas voltadas para as culturas populares. Nas palavras de Gilberto Gil (2007 p. 29):

Hoje vivemos um nítido processo de metropolização no popular, onde as metrópoles se apropriam do popular em suas linguagens, conteúdos e, principalmente, em seus produtos, o que tem sido importante para a difusão e valorização das culturas populares, que ganharam status e valor de mercado e, com isso, mais condições de sustentabilidade. Mas também precisamos voltar-nos para a inversão deste processo: para a popularização na metrópole, ou seja, estabelecer estruturas, canais e oportunidades para que as culturas populares possam dispor das condições de produção e difusão das metrópoles, para que possam dispor de instrumentos e meios qualificados para produzirem e divulgarem suas criações.

É este sentido de popularização na metrópole, de empoderamento das culturas populares, que balizou o discurso da gestão Gilberto Gil e orientou o desenho de políticas voltadas para a área. Em 2010 o MinC publicou o Plano Setorial para Culturas Populares, no qual enumera e descreve as ações da pasta voltadas para a área. As primeiras ações descritas foram o I e II Seminário Nacional de Políticas Públicas para as Culturas Populares, realizados, respectivamente, em 2005 e 2006, e que reuniram gestores públicos, acadêmicos e representantes das culturas populares para a discussão de diretrizes para as políticas do MinC. Foi também neste primeiro seminário que foi criada a Rede das Culturas Populares. Destes seminários surgiram também duas publicações que sistematizam as discussões e apresentações, das quais me utilizo largamente neste trabalho, a saber: os anais do I Seminário de Políticas Públicas para as Culturas Populares e os anais do I Encontro Sul-Americano das Culturas Populares e II Seminário Nacional de Políticas Públicas para as Culturas Populares. Nestas publicações, além de em textos de acadêmicos(as) e gestores(as) do MinC sobre o tema, vêm à tona também as vozes de diversos mestres e mestras das culturas populares falando sobre as políticas públicas para as culturas populares, os desafios de acesso ao Estado e as principais demandas para com este. Os seminários configuraram-se, portanto, como um raro espaço de contato direto e intenso das culturas populares com o Estado e a academia, produzindo um rico material de referência para a elaboração de políticas públicas. Além disso, o MinC lançou editais setoriais, específicos para as culturas populares, dentre os quais estão os Prê- 
mios Culturas Populares lançados nos anos de 2007, 2008, 2009 e 2012, que, por serem menos burocráticos do que os editais realizados via leis de incentivo, contribuem para o acesso de grupos e mestres(as) de cultura popular aos recursos públicos.

Cabe destacar também a ação do Instituto do Patrimônio Histórico e Artístico Nacional (IPHAN), que, por meio da implementação do Plano Nacional do Patrimônio Imaterial (PNPI), o qual, entre 2003 e 2010, realizou o registro e inventariação de várias expressões e celebrações das culturas populares, assim como elaborou e implementou políticas de salvaguarda para estas. Neste período, o IPHAN realizou, por exemplo, a inventariação, baseado na metodologia do Inventário Nacional de Referências Culturais (INRC), do Bumba Meu Boi do Maranhão, do Tambor de Crioula do Maranhão, do Jongo do Sudeste e do Samba de Roda da Bahia; todas manifestações das culturas populares. Com o processo de inventariação, realizado com a participação dos(as) detentores(as) destes saberes, abriu-se o caminho tanto para a proteção destes bens culturais por parte do Estado, como para a promoção de políticas de salvaguarda, que podem incluir a construção de centros de referências e memória, legalização de ocupações territoriais e ações de proteção da propriedade intelectual dos(as) detentores(as) de saberes.

Outro programa que merece destaque é o Cultura Viva, que tem como ação prioritária a criação dos Pontos de Cultura. Segundo Célio Turino (2007, p. 67), "o Ponto de Cultura é a potencialização das energias criadoras dos nossos cidadãos, bem como das ações que já são desenvolvidas pelas comunidades". No entanto, os Pontos de Cultura não são destinados apenas para as culturas populares, apesar de as abrangerem também, mas pretendem "[...] promover um mapeamento e uma cartografia da imensa variedade de expressão da cultura do nosso povo" (TURINO, 2007 p. 67). Os Pontos de Cultura visam também à autonomia das comunidades, não se configurando como territórios estatais, mas, sim, como pontos de intersecção entre sociedade e Estado. Buscando a autonomia dos Pontos de Cultura, além de recursos repassados pelo MinC para a criação e manutenção dos Pontos de Cultura, o programa também prevê a montagem de um pequeno estúdio multimídia que permita a produção local de recursos multimídia e gravações (TURINO, 2007). Outra iniciativa do programa que merece destaque é o lançamento periódico de editais de fomento de participação restrita aos Pontos de Cultura, garantindo, assim, um acesso diferenciado destes às políticas públicas. Deste modo, o programa Cultura Viva não busca apenas a integração das culturas populares à lógica da espetacularização, mas também fornece elementos que podem permitir maior autonomia e empoderamento por parte das comunidades. Neste sentido, creio que o programa Cultura Viva é uma das ações mais efetivas do MinC com relação à necessidade de levar em conta os modos de vida das culturas populares na formulação e implementação das políticas públicas.

O projeto Encontro de Saberes, realizado pela parceria entre o MinC (através da Secretaria da Identidade e da Diversidade Cultural), o Ministério da Educação (MEC) (através da Secretaria de Educação Superior) e a Universidade de Brasília (UnB) (através do Instituto Nacional de Ciência e Tecnologia de Inclusão no Ensino Superior e na Pesquisa), também merece destaque. O projeto está inserido na Câmara Interministerial de Educação e Cultura, criada em 2006 e regulamentada pela Portaria Normativa Interministerial (MinC e Ministério da Educação) de 20075. Deste modo, o Encontro de Saberes é decorrente da ação intersetorial entre órgãos da admi-

Disponível em <http://www2.cultura.gov.br/site/2010/06/09/sidminc-realizou-a-primeira-oficina-do-projeto-encontro-dos-saberes-nesta-terca-feira/>. Acessado em 05 ago. 2013. 
nistração direta federal e a academia, mostrando que a complexidade que envolve a elaboração de políticas públicas para as culturas populares exige o trabalho conjunto de instituições públicas.

No projeto, que teve início em 2010, mestres(as) das culturas populares, tradicionais e indígenas atuam como docentes da UnB, ministrando aulas a alunos(as) de graduação sobre os saberes e fazeres tradicionais na disciplina Artes e Ofícios dos Saberes Tradicionais, ofertada pelo Departamento de Antropologia e coordenada pelo professor José Jorge de Carvalho. Tal projeto visa expandir as fronteiras da universidade que ainda separam e hierarquizam os saberes acadêmicos e tradicionais. Hoje tal projeto já se encontra em sua quarta edição a partir da oferta da referida disciplina para o segundo semestre letivo de 2013 na UnB. O Encontro de Saberes contribui, portanto, para a legitimação dos saberes tradicionais das culturas populares dentro do espaço acadêmico que, historicamente, relegou a estes o lugar de objetos de conhecimento em detrimento ao de sujeitos. Por isso, a presença dos mestres(as) como professores(as) é uma questão central do projeto, visando tanto à possibilidade de que alunos(as) tomem contato com os saberes e os processos de aprendizagem tradicionais, como o reconhecimento da legitimidade destes saberes enquanto formas de conhecimento a serem não apenas reconhecidas pelas instituições hegemônicas, mas também promovidas por estas.

\section{Considerações finais}

Em 2008, Gilberto Gil pediu exoneração do cargo de Ministro da Cultura (MinC) por motivos pessoais e foi sucedido por Juca Ferreira, então secretário-executivo do MinC. Ferreira deu continuidade à gestão de Gil, ficando no cargo até o fim do segundo mandato de Lula, em 2012. Com a eleição de Dilma Roussef para a presidência, foi escolhida Ana de Holanda para a pasta. A partir de então, o MinC passou por um momento de instabilidade política, especialmente no que diz respeito às políticas e ações mais progressistas dos anos anteriores. Com relação a isto, o processo de revisão da Lei Rouanet, já emperrado, foi engavetado, assim como a revisão dos direitos autorais no Brasil. Em sua breve passagem pela pasta, ficou claro um viés conservador por parte da ex-ministra com relação às duas gestões anteriores, ainda que fossem do mesmo partido. Outros problemas ocorreram, como as queixas recorrentes de Pontos de Cultura com relação a atrasos no repasse de verbas do MinC. O clima de instabilidade fortificou-se na gestão de Ana de Holanda, acarretando sua substituição por Marta Suplicy na gestão da pasta em 2012. Em uma de suas primeiras ações frente à pasta, Suplicy mostrou-se aberta à ampliação de políticas setoriais e afirmativas na pasta, como o lançamento, em 2013, de cinco editais de financiamento a projetos culturais restritos a criadores(as) e produtores(as) negros(as).

Ainda que durante os mais de dez anos de governos do Partido dos Trabalhadores (PT) tenham assistido a distintos momentos na gestão do MinC, é possível afirmar que, neste período, houve uma mudança substancial no papel da pasta e no entendimento que esta passou a ter do que é cultura e do que são políticas culturais. Assim, o MinC elaborou e implementou políticas com foco na diferença, na melhor distribuição de recursos públicos e no empoderamento de setores historicamente marginalizados, como é o caso das culturas populares. Como observa Alves (2011b), no entanto, o foco das políticas para as culturas populares no período recaiu mais sobre as expressões culturais do que sobre as populações, mostrando que - apesar de uma mudança substancial no discurso oficial - ainda existem enormes desafios para que o MinC realmente atinja estes objetivos. 
Promover políticas para uma manifestação cultural - é importante ressaltar não significa necessariamente ter como público alvo os(as) detentores(as) de tais saberes, pois as manifestações culturais podem ser apropriadas por outros grupos: neste sentido, um disco de samba de uma cantora branca e de classe alta pode ser financiado via lei de incentivo pelo MinC, mas tal ação não atinge os sambistas negros das periferias que vivem o samba como uma tradição comunitária e que também necessitam de políticas públicas para atuarem enquanto artistas populares.

Por outro lado, muitos dos mecanismos planejados (como o Sistema Nacional de Cultura e o Sistema Nacional de Informações e Indicadores Culturais) ainda estão longe de ser completamente implementados; as metas e estratégias do Plano Nacional de Cultura (PNC) ainda carecem, em sua maioria, da elaboração e implementação de políticas culturais; o não abandono dos mecanismos de renúncia fiscal da iniciativa privada é contraproducente para uma melhor distribuição de recursos públi$\cos$, pois seu desenho privilegia os setores mais poderosos e profissionalizados (SARKOVAS, 2005); a desburocratização do acesso a recursos públicos e a capacitação técnica de setores culturais marginalizados, apesar de algumas tentativas, como os Pontos de Cultura e realização de oficinas de capacitação pelo MinC, ainda são incipientes e, por fim, a produção de informações e estatísticas sobre o setor de cultura no Brasil ainda é insuficiente, especialmente em relação às culturas populares.

É preciso, no entanto, ressaltar que as gestões Gilberto Gil/Juca Ferreira foram um marco de mudança na concepção do papel do Estado na cultura. Este deixou de ser um coadjuvante da decisão privada do exclusivismo das leis de incentivo e assumiu um papel de fomentador do desenvolvimento cultural, buscando distribuir recursos, empoderar setores sociais e construir um diálogo entre o Estado e os sujeitos da cultura. Ainda que seja discutível a questão de até qual ponto estes objetivos foram atingidos, não há como negar que a proposição destes objetivos e tentativa de colocá-los em prática foi uma inovação no cenário das políticas culturais no Brasil. Além disso, no caso das culturas populares, o discurso dos(as) gestores(as) do MinC mostrou-se sensível a uma série de questões pertinentes, tais como desburocratização do acesso a recursos, a preocupação com os modos de vida e o empoderamento e a autonomia das comunidades. Dados do MinC mostram que os recursos para a área das culturas populares aumentou significativamente em relação à gestão anterior, passando de $\mathrm{R} \$ 17.428 .862,00$ no período 1995 a 2003 para $\mathrm{R} \$ 25.045 .774,00$ no período 2004 a 2009. Em outras palavras, os recursos destinados para a área passaram de uma média anual de $\mathrm{R} \$ 1.936 .450,00$ no primeiro período para uma de $\mathrm{R} \$$ 4.174.296,00 no segundo (MINISTÉRIO DA CULTURA, 2010).

No entanto, creio que existem algumas ressalvas importantes a serem feitas. A primeira é a de que ainda falta mais transparência no acesso a informações, uma vez que há poucas publicações sobre o monitoramento e a avaliação da implementação destas políticas e as que existem trazem poucas informações. Há, ainda, uma quase que completa escassez de dados estatísticos oficiais sobre as culturas populares. A principal fonte de dados oficiais sobre as culturas populares é o Suplemento de Cultura da MUNIC de 2006, pesquisa levada a cabo pelo Instituto Brasileiro de Geografia e Estatística (IBGE): o foco do suplemento, no entanto, é mapear a existência de equipamentos e atividades culturais nos municípios brasileiros e limita-se a apontar a existência de festas e manifestações populares nos municípios, dados levantados junto à gestores(as) municipais. Ademais, mesmo que o MinC disponibilize uma série de dados sobre o planejamento 
e a execução do orçamento da pasta, existem poucas desagregações dos dados, especialmente no caso das culturas populares. Por exemplo, não há dados acerca de quanto cada manifestação das culturas populares recebeu em recursos do MinC; não há desagregação dos dados da destinação dos recursos por sexo, raça ou etnia; não há informações quanto aos recursos terem sido ou não destinados às produtoras profissionais que tinham projetos com as culturas populares ou se as próprias culturas populares acessaram os recursos através de CNPJ próprio. Além disso, há informações sobre o orçamento geral de cada programa, mas quando a questão é desagregar os dados para saber quais grupos e produtores(as) estão acessando estas políticas, de que região, de que faixa de renda, de que classificação racial, de qual sexo, entre outras questões importantes, os dados inexistem. Não há como abordar a distribuição dos recursos e desburocratização do acesso a eles se o próprio Estado não produz dados para que fique claro como os grupos estão, ou não, acessando tais recursos.

No caso das políticas públicas voltadas para as culturas populares tal questão é central, pois o financiamento, por exemplo, de um festival de cultura popular não implica que as culturas populares estão sendo incluídas socialmente ou ganhando autonomia. Muitas vezes os projetos de cultura popular são propostos por grupos de produtores culturais ou artistas profissionais que têm pouca, ou nenhuma, conexão com a culturas populares. É necessário que o MinC tenha controle sobre o acesso aos recursos daquelas políticas voltadas especificamente para as culturas populares e outros grupos marginalizados. É importante encarar tais políticas como políticas afirmativas, que devem buscar a superação de injustiças históricas e a promoção da igualdade em vários âmbitos, como social, econômico, étnico-racial e de gênero. Neste sentido, a produção de dados, sejam eles qualitativos ou quantitativos, sobre a implementa- ção e avaliação de políticas públicas é um dever do Estado, para que a gestão pública seja transparente e as políticas públicas mais eficientes.

Por fim, é necessária a criação e ampliação de programas que, como o Cultura Viva, compreendam as culturas populares como um modo de vida em que se integram distintas dimensões, como religiosidade, saúde, agricultura, manifestações artísticas, parentesco, entre outras. Para isso, é preciso que as políticas públicas sejam transversais não apenas no âmbito da estrutura interna do MinC, mas também com relação a outros ministérios, como no caso das políticas para comunidades quilombolas que atravessam vários órgãos federais, como o MinC, o Ministério do Desenvolvimento Social (MDS), a Secretaria de Políticas de Promoçãoda Igualdade Racial da Presidência da República (SEPPIR/PR) e o Instituto Nacional de Colonização e Reforma Agrária (INCRA).

Para concluir, recorro novamente à argumentação de Veena Das e Deborah Poole, os quais afirmam que o Estado sempre se constrói como um projeto incompleto (DAS; POOLE, 2004). Neste sentido, a história da relação entre as culturas populares e o Estado no Brasil é de marginalização das primeiras e de sua incorporação seletiva e reificante pelo segundo. Ainda assim, é possível ver como esta relação do Estado com suas margens também transforma o próprio o Estado e a maneira como este se relaciona com as culturas populares, especialmente a partir do momento em que estas se organizam coletivamente e demandam, frente ao Estado, os direitos garantidos por marcos legais nacionais e internacionais, recursos e reconhecimento. Tal mudança foi gradual, mas é a partir do governo Lula e da gestão Gilberto Gil que ela se consolidou. Assim, ainda que a marginalização, perante o Estado, das culturas populares seja grande, é possível perceber como o discurso e a ação do Estado paulatinamente se transforma na relação com a ação política destes grupos. 
Referências

1. ACCO, M. Diálogos e políticas para inclusão das culturas populares. In: SEMINÁRIO DE POLÍTICAS PÚBLICAS PARA AS CULTURAS POPULARES, II, Brasília, 2007, Ministério da Cultura, p. 63-65.

2. ALVES, E. P. M. A economia simbólica da cultura popular sertanejonordestina. Maceió, Editora UFAL, 2011 a.

3. O lugar das culturas populares no sistema MinC: o sertão e a institucionalização das políticas culturais para as culturas populares. In:

Políticas culturais para as culturas populares no Brasil contemporâneo. Maceió, EdUFAL, 2011b. P. 125-169.

4. BARBALHO, A. Políticas culturais no Brasil: identidade e diversidade sem diferença. In: ; RUBIM, Antônio Albino Canelas. Políticas culturais no Brasil. Salvador, EDUFBA, 2007. P.37-60.

5. BRASIL. Lei $n^{\circ} 12.343$, de 2 de dezembro de 2010. Institui o Plano Nacional de Cultura - PNC, cria o Sistema Nacional de Informações e Indicadores Culturais e dá outras providências.

6. CALABRE, L. Políticas culturais no Brasil. Rio de Janeiro: Editora FGC, 2009.

7. CAVALCANTI, M. L. Culturas populares: múltiplas leituras. In: SEMINÁRIO DE POLÍTICAS PÚBLICAS PARA AS CULTURAS POPULARES, I, Brasília, 2005, Ministério da Cultura, p. 28-33.

8. CARVAlHO, J. J. Contra a pirâmide de prestígio e por ações afirmativas. In: SEMINÁRIO DE POLÍTICAS PÚBLICAS PARA AS CULTURAS POPULARES, I, Brasília, 2005, Ministério da Cultura, p. 34-37.

9. Espetacularização e canibalização das culturas populares. In:
SEMINÁRIO DE POLÍTICAS PÚBLICAS PARA AS CULTURAS POPULARES, II, Brasília, 2007, Ministério da Cultura, p. 78-101.

10. DAS, V.; POOLE, D. State and its margins: comparative ethnographies. In: DAS, Veena; POOLE, Deborah (orgs.). Anthropology in the margins of state. Santa Fe, School of American Research Press, cap. 1, p. 3-33, 2004.

11. DELEUZE, G.; GUATTARI, F. Mil platôs: capitalismo e esquizofrenia vol. 5. São Paulo, Editora 34, 1997.

12. GIL, G. Palavras do exmo senhor Ministro da Cultura Gilberto Passos Gil Moreira. In: SEMINÁRIO DE POLÍTICAS PÚBLICAS PARA AS CULTURAS POPULARES, II, Brasília, 2007, Ministério da Cultura, p. 29.

13. GUimarãeS, A. S. A. Classes, raças e democracia. São Paulo, Editora 34, 2002.

14. HERZFELD, M. Cultural intimacy: social poetics in the nation-state. New York/London, Routledge, 1997.

15. LATOUR, B. Reassembling the social: an introduction to actor-network-theory. Oxford, Oxford University Press, 2005.

16. MAMBERTI, S. Culturas populares brasileiras: a esperança de construir um futuro. In: SEMINÁRIO DE POLÍTICAS PÚBLICAS PARA AS CULTURAS POPULARES, I, Brasília, 2005, Ministério da Cultura, p. 118-121.

17. MANEVY, R. A. Cultura, novos modelos de desenvolvimento. In: SEMINÁRIO DE POLÍTICAS PÚBLICAS PARA AS CULTURAS POPULARES, II, Brasília, 2007, Ministério da Cultura, p. 56-58.

18. MINISTÉRIO DA CULTURA. Plano setorial para as culturas populares. 2010. Disponível em: http:// www.cultura.gov.br/cnpc/wp-content/ uploads/2011/07/plano-setorial-de-cul- 
turas-populares.pdf. Acesso em: 13 jun. 2012.

19. PORTA, P. Economia da cultura: um setor estratégico para o país. Disponível em: http://www.cultura.gov. br/site/2008/04/01/economia-da-cultura-um-setor-estrategico-para-o-pais/. Acesso em: 06 jun. 2012.

20. RUBIM, A. A. C. Políticas culturais no Brasil: tristes tradições, enormes desafios. In: BARBALHO, Alexandre; (orgs.). Políticas culturais no Brasil. Salvador, EDUFBA, 2007. P.11-36.

21. . Plano Nacional de Cultura em debate. Políticas Culturais em Revista, Salvador, v. 2, p. 59-72, 2008a.

22. . Políticas nacionais de cultura: o documento de 1975 e a proposta do governo Lula/Gil. Políticas Culturais em Revista, Salvador, V.2, p.73-90, 2008b.

23. SARKOVAS, Y. Caminhos e descaminhos culturais do governo FHC. 2003. Disponível em: http://comatitude. com.br/2003/02/01/os-caminhos-e-descaminhos-culturais-do-governo-fhc/. Acesso em: 15 de jun. 2012.

24. SEGATO, R. Raça é signo. Brasília, DAN-UnB, Série Antropologia, $\mathrm{N}^{\circ}$ 372, 2005, p.1-16.

25. TURINO, C. A cultura como energia criadora dos cidadãos. In: SEMINÁRIO DE POLÍTICAS PÚBLICAS PARA AS CULTURAS POPULARES, II, Brasília, 2007, Ministério da Cultura, p. 67-70.

26. UNESCO. Convenção sobre a proteção e promoção da diversidade das expressões culturais. 2007. Disponível em: http://unesdoc.unesco.org/ images $/ 0015 / 001502 / 150224$ por.pdf. Acesso em: 13 jun. 2012.

27. VILHENA, L. R. Projeto e missão: o movimento folclórico brasileiro 1947-1964. Rio de Janeiro, FUNARTE/Editora FGV, 1997.
28. YÚDICE, G. A conveniência da cultura. Belo Horizonte, Editora UFMG, 2004. 